\title{
Statistical Modeling of Tear Strength for One Step Fixation Process of Reactive Printing and Easy Care Finishing
}

\author{
FAREHA ASIM*, AND MUZZAFFAR MAHMOOD** \\ RECEIVED ON 25.03.2016 ACCEPTED ON 11.05.2016 \\ ABSTRACT
}

\begin{abstract}
Statistical modeling imparts significant role in predicting the impact of potential factors affecting the one step fixation process of reactive printing and easy care finishing. Investigation of significant factors on tear strength of cotton fabric for single step fixation of reactive printing and easy care finishing has been carried out in this research work using experimental design technique. The potential design factors were; concentration of reactive dye, concentration of crease resistant, fixation method and fixation temperature. The experiments were designed using DoE (Design of Experiment) and analyzed through software Design Expert. The detailed analysis of significant factors and interactions including ANOVA (Analysis of Variance), residuals, model accuracy and statistical model for tear strength has been presented. The interaction and contour plots of vital factors has been examined. It has been found from the statistical analysis that each factor has an interaction with other factor. Most of the investigated factors showed curvature effect on other factor. After critical examination of significant plots, quadratic model of tear strength with significant terms and their interaction at $\alpha=0.05$ has been developed. The calculated correlation coefficient, $R^{2}$ of the developed model is 0.9056 . The high values of correlation coefficient inferred that developed equation of tear strength will precisely predict the tear strength over the range of values.
\end{abstract}

Key Words: Design of Experiment, Easy Care Finishing, Reactive Printing, Statistical Modelling, Tear Strength.

\section{INTRODUCTION}

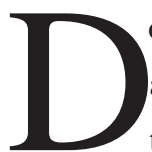

oE [1-6] is an important tool used to analyze and improve the existing process as well as for the development of new process. Various hypothetical and investigational studies have been carried out depicting the comprehensive information of process factors and operating parameters of reactive dye printing and crease resistance finishing [7-14]. Furthermore, reports in literature revealed that one step fixation process of reactive dye printing and easy care finishing using cotton fabric has already been examined [15-16]. This paper investigates effects on tear strength for single step fixation of reactive printing and easy care finishing of cotton fabric. The statistical model for tear strength has been developed to predict the relationship of different factors being studied. The statistical analysis of tear strength of cotton fabric comprising ANOVA

* Department of Textile Engineering, NED University of Engineering \& Technology, Karachi.

** Department of Mechatronics Engineering, PAF, Karachi Institute of Electrical Technology, Karachi.

Mehran University Research Journal of Engineering \& Technology, Volume 36, No. 3, July, 2017 [p-ISSN: 0254-7821, e-ISSN: 2413-7219] 
(Analysis of Variance), model accuracy analysis, and analysis of residual has been presented in section 2 and 3. The experiment design is completely randomized with two replicates. The results of tear strength were examined through statistical software Design Expert.

\section{EXPERIMENTAL}

\section{$2.1 \quad$ Fabric}

Commercially pre-treated and mercerized cotton satin fabric having gsm of $136 \mathrm{~g} / \mathrm{m}^{2}$ and construction of 40x40/ 130x73 has been used for this work.

\section{$2.2 \quad$ Chemicals}

The easy care finishing bath was prepared by adding $\mathrm{MgCl}_{2}$ (Magnesium Chloride), wetting agent (Imercol PCLF), an-ionic and silicon softener (Ceranine L \& Solusoft MW). The easy care finishing agent used was modified dimethyloldihydroxy ethylene urea namely Arkofix NEC (Archroma). The final finish bath was prepared with different concentrations of crease resistant as outlined in Table 1.

Sodium alginate, sodium bicarbonate, urea, reduction inhibitor and sodium hexametaphosphate was added to prepare the stock paste for printing. However, urea is not added in the stock being prepared for the tests using the fixation method of E-Control. The final print paste for respective test run was formed by adding different concentration of reactive dye namely Drimarine Red P2B (Archroma), based on the MCT (Monochlorotriazine) reactive group as stated in Table 1.

\subsection{Method}

The completely randomized run order of $2^{1} .3^{3}$ mixed factorial design having 54 runs with two replicates has been generated using software Design Expert. The experimental trials have been conducted according to the run order. The one step fixation of printing and easy care finishing is conducted as follows: At first, ready to print fabric was padded with the easy care finishing liquor such that pickup of the fabric should maintain to $70 \%$. In the second stage finished fabric was dried at $100^{\circ} \mathrm{C}$ for $1 \mathrm{~min}$. In the third stage, the fabric was printed with the reactive print paste. The treated fabric was finally fixed in one step using different fixation methods and temperature as specified in Table 1. The fixed samples were then rinsed, soaped, washed and dried.

\subsection{Evaluation of Tear Strength}

After conducting the experimental runs, tear strength of each sample processed from one step fixation of reactive printing and easy care finishing were evaluated using Elmandorf tear strength tester using standard test method ASTM D1424. Two replicates of each test were conducted to maintain the accuracy of the results. Before conducting the test samples were conditioned for four hours in standard conditions.

TABLE 1. POTENTIAL DESIGN FACTORS AND LEVELS OF $2^{1} \cdot 3^{3}$ MIXED FACTORIAL DESIGN [17]

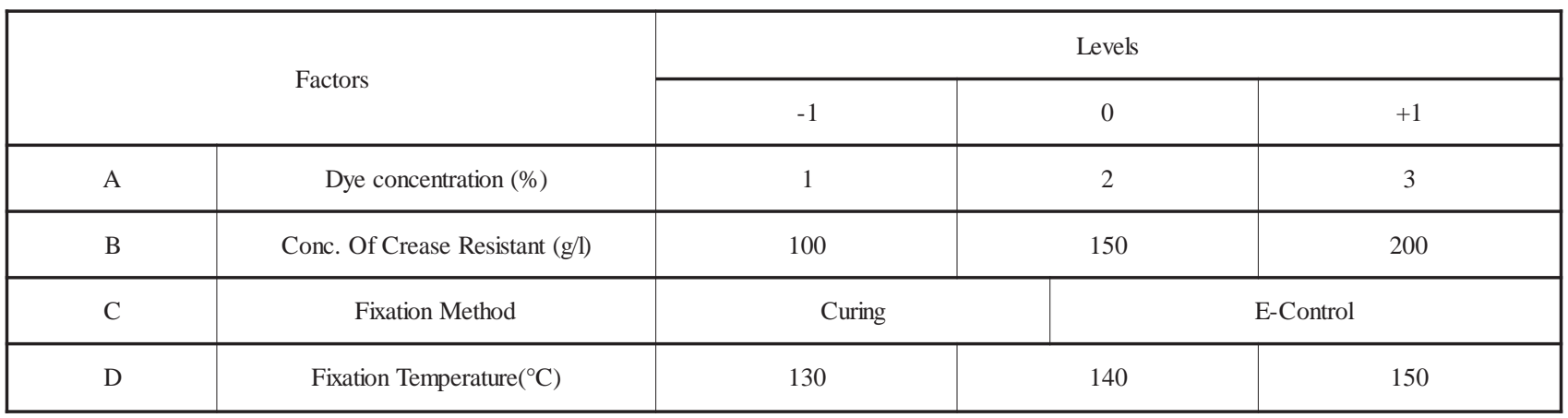

Mehran University Research Journal of Engineering \& Technology, Volume 36, No. 3, July, 2017 [p-ISSN: 0254-7821, e-ISSN: 2413-7219] 


\section{RESULTS AND DISCUSSION}

The tear strength values were statistically analyzed using software Design Expert. Prior to the ANOVA model accuracy has been examined through various residuals plots. The four plots of residuals were examined and presented in Fig. 1(a-d). The study of residuals plots

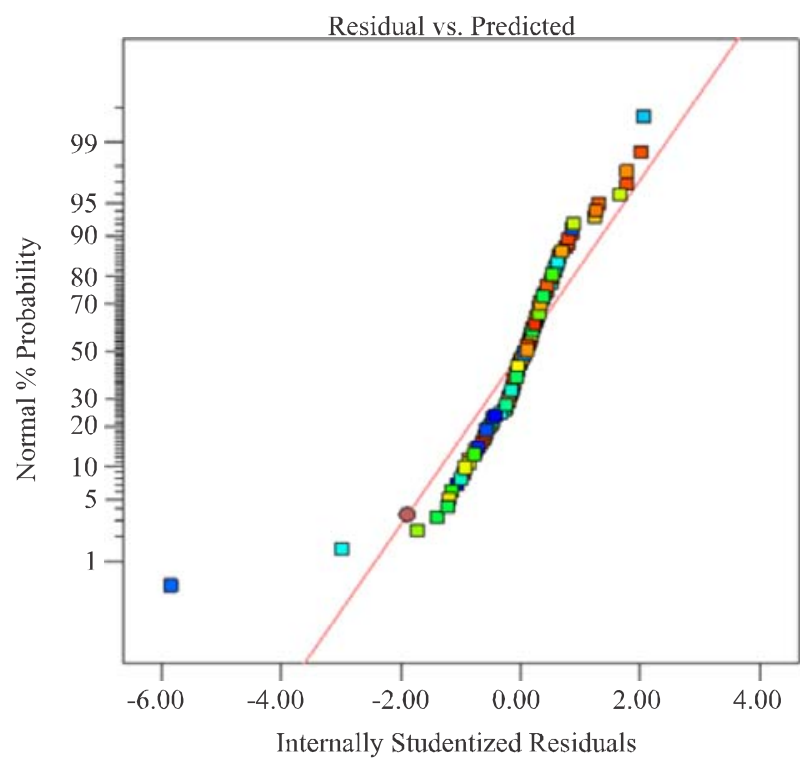

(a)

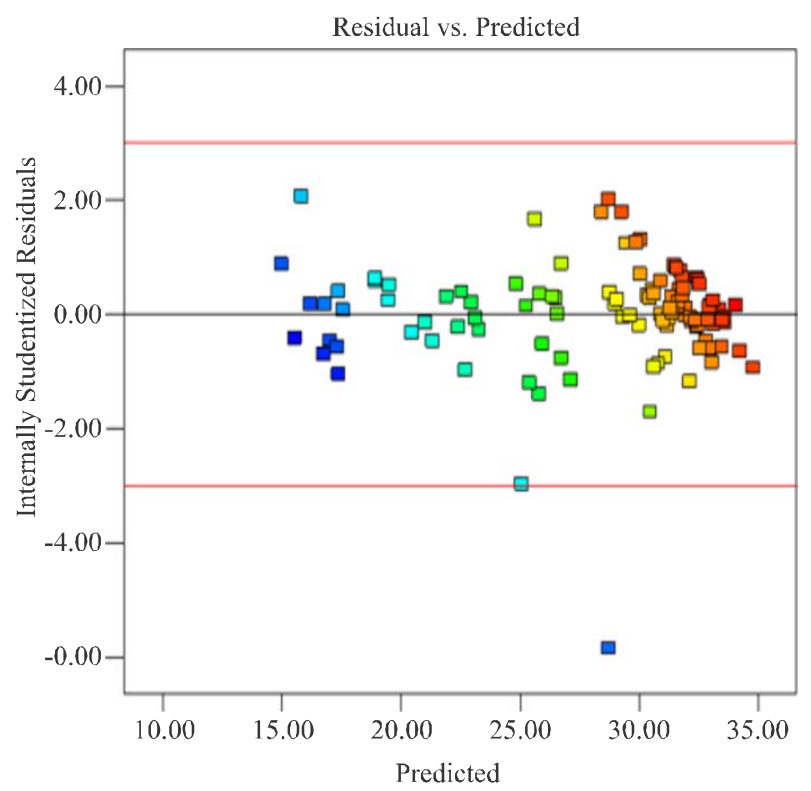

(c) shown that the residuals of tear strength model are normally distributed and significant evidence of possible outliers was not found. So the tear strength model can be used to predicted results with 95\% confidence interval. The ANOVA was conducted for the tear strength model. The results of significant factors are stated in Table 2.

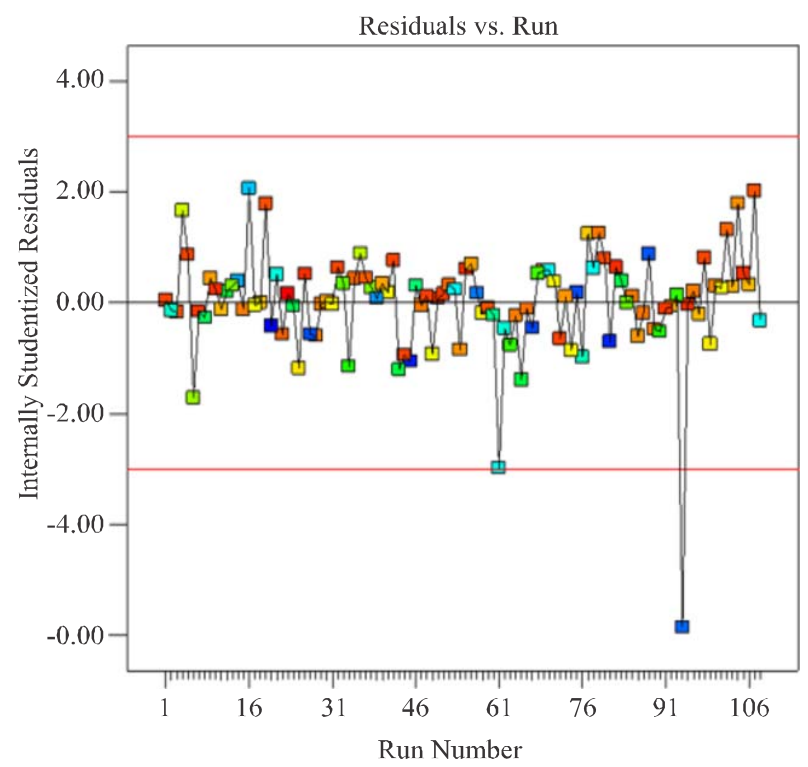

(b)

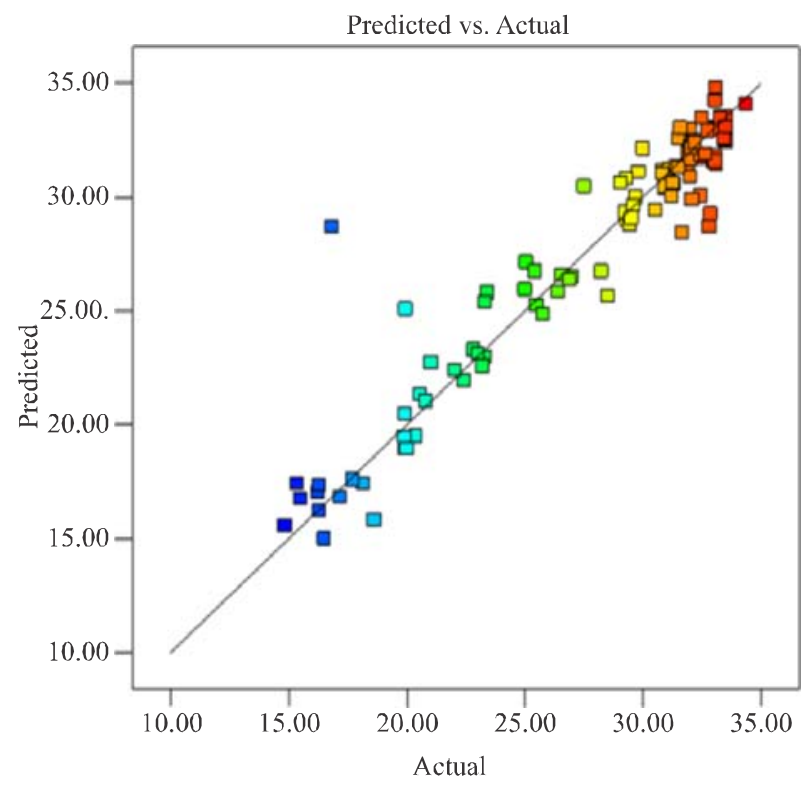

(d)

FIG. 1. RESIDUAL PLOTS FOR TEAR STRENGTH

Mehran University Research Journal of Engineering \& Technology, Volume 36, No. 3, July, 2017 [p-ISSN: 0254-7821, e-ISSN: 2413-7219] 
The fifth model has been selected for tear strength. The Model p-value comes out to $<0.0001$ which indicates that tear strength is significant with respect to one step fixation process. The analysis demonstrated that two out of four factors are vital for tear strength for theone step fixation process of reactive printing and easy care finishing. However, various interactions have been identified significant for the specified process such as interaction of concentration of dye with fixation method and temperature (AC and $\mathrm{AD}$ ), concentration of crease

TABLE 2. ANOVA FOR TEAR STRENGTHOF SIGNIFICANT MODEL TERMS [17]

\begin{tabular}{|c|c|c|c|c|c|c|}
\hline Source & $\begin{array}{l}\text { Sum of } \\
\text { Squares }\end{array}$ & $\begin{array}{c}\text { Degree of } \\
\text { Freedom }\end{array}$ & $\begin{array}{l}\text { Mean } \\
\text { Square }\end{array}$ & F-value & Prob $>F$ & Remarks \\
\hline Block & 29.31 & 1 & 29.31 & & & \\
\hline Model & 3144.47 & 48 & 65.51 & 11.60 & $<0.0001$ & \multirow{22}{*}{ Significant } \\
\hline A-Chroma & 177.06 & 1 & 177.06 & 31.35 & $<0.0001$ & \\
\hline D-Fixation emperature & 61.00 & 1 & 61.00 & 10.80 & 0.0017 & \\
\hline $\mathrm{AB}$ & 28.60 & 1 & 28.60 & 5.06 & 0.0283 & \\
\hline AC & 91.79 & 1 & 91.79 & 16.25 & 0.0002 & \\
\hline $\mathrm{AD}$ & 133.16 & 1 & 133.16 & 23.57 & $<0.0001$ & \\
\hline $\mathrm{BD}$ & 63.28 & 1 & 63.28 & 11.20 & 0.0014 & \\
\hline CD & 48.04 & 1 & 48.04 & 8.50 & 0.0050 & \\
\hline $\mathrm{A} 2$ & 56.80 & 1 & 56.80 & 10.05 & 0.0024 & \\
\hline D2 & 66.20 & 1 & 66.20 & 11.72 & 0.0011 & \\
\hline ACD & 29.53 & 1 & 29.53 & 5.23 & 0.0259 & \\
\hline $\mathrm{AD} 2$ & 60.44 & 1 & 60.44 & 10.70 & 0.0018 & \\
\hline CD2 & 174.69 & 1 & 174.69 & 30.93 & $<0.0001$ & \\
\hline A2BD & 25.20 & 1 & 25.20 & 4.46 & 0.0390 & \\
\hline A2CD & 60.17 & 1 & 60.17 & 10.65 & 0.0018 & \\
\hline B2CD & 22.73 & 1 & 22.73 & 4.02 & 0.0496 & \\
\hline A2B2D & 41.06 & 1 & 41.06 & 7.27 & 0.0092 & \\
\hline A2BD2 & 54.92 & 1 & 54.92 & 9.72 & 0.0028 & \\
\hline $\mathrm{A} 2 \mathrm{CD} 2$ & 42.27 & 1 & 42.27 & 7.48 & 0.0082 & \\
\hline $\mathrm{AB} 2 \mathrm{CD}$ & 39.78 & 1 & 39.78 & 7.04 & 0.0103 & \\
\hline $\mathrm{B} 2 \mathrm{CD}$ & 23.95 & 1 & 23.95 & 4.24 & 0.0440 & \\
\hline Residual & 327.62 & 58 & 5.65 & & & \\
\hline Lack of Fit & 191.62 & 53 & 3.62 & 0.13 & 1.0000 & \multirow{5}{*}{ Not Significant } \\
\hline Pure Error & 136.00 & 5 & 27.20 & & & \\
\hline Cor Total & 3501.40 & 107 & & & & \\
\hline Std. Dev. & 2.38 & C.V\% & 8.49 & PRESS & 964.09 & \\
\hline $\mathrm{R} 2$ & 0.9056 & Adj R2 & 0.8276 & Pred R2 & 0.7223 & \\
\hline
\end{tabular}

Mehran University Research Journal of Engineering \& Technology, Volume 36, No. 3, July, 2017 [p-ISSN: 0254-7821, e-ISSN: 2413-7219] 
resistant and fixation temperature (BD) and fixation method and temperature (CD). The plots of numerous momentousinteractions of tear strength have been presentedfrom Figs. 2-5, whereas some cruical contour plots have been shown from Figs. 6-8. The ANOVA illustrates that the tear strength of the one step fixation process primarily depends on the concentration of reactive dye and fixation temperature. Nevertheless, the interaction and curvature effect of concentration of reactive dye and crease resistant, fixation method and temperature should be critically examined before predicting the statistical model. The interaction plot shown

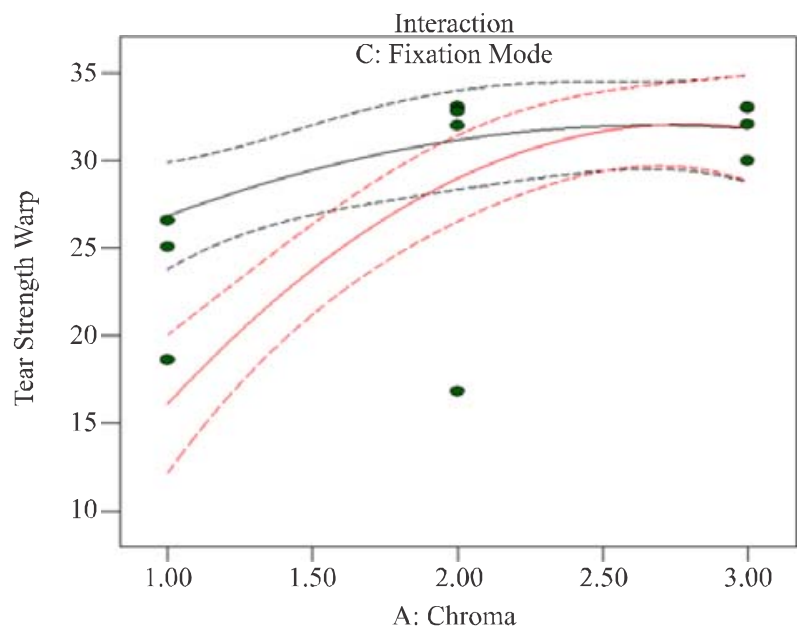

FIG. 2. INTERACTION OF DYE CONCENTRATION AND FIXATION METHOD

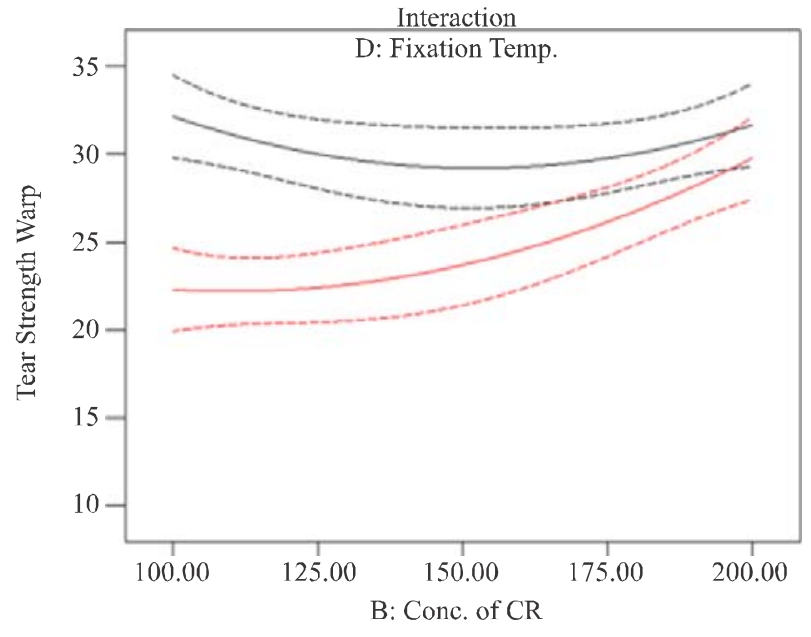

FIG. 3. INTERACTION OF DYE CONCENTRATION AND FIXATION TEMPERATURE in Fig. 2 depicts that at lower value of dye concentration curing mode of fixation gives higher value of tear strength, however at higher values both Econtrol and curing mode of fixation gives comparable results of tear strength. Figs. 3-4 revealed that irrespective of concentration of dye and crease resistant, fixation temperature of 130-135p Cprovides improved values of tear strength. The interaction plot of fixation mode and fixation temperature shown in Fig. 5 ascertained that Econtrol fixation method at $130-135^{\circ} \mathrm{C}$ can be effectively used for the single step fixation process for getting higher values of tear strength. By considering all the significant mian factors and

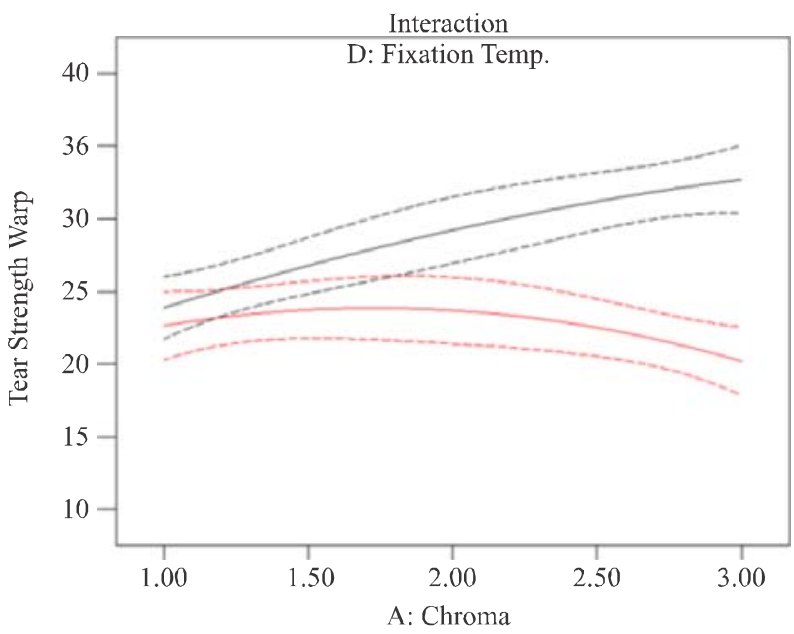

FIG. 4. INTERACTION OF CONCENTRATION OF CREASE RESISTANT AND FIXATION TEMPERATURE

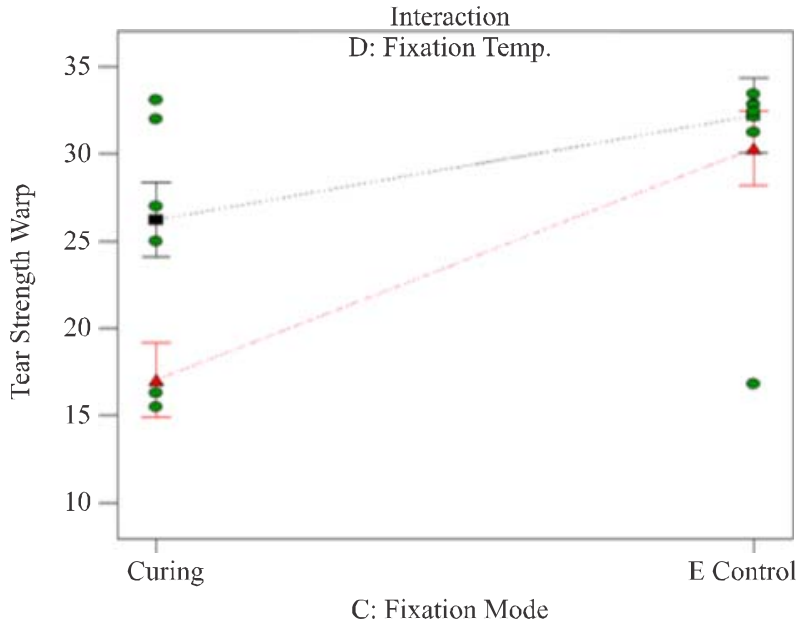

FIG. 5. INTERACTION OF FIXATION METHODAND FIXATION TEMPERATURE

Mehran University Research Journal of Engineering \& Technology, Volume 36, No. 3, July, 2017 [p-ISSN: 0254-7821, e-ISSN: 2413-7219] 
interaction statistical model of tear strength has been developed through software Design Expert and presented in Equation (1). The developed equation shall explicitlypredict the relationship of significant factors and interactions of tear strength in one step fixation process of reactive printing and easy care finishing process over the range of values bieng considered in this research work [17].

\section{Statistical Model of Tear Strength}
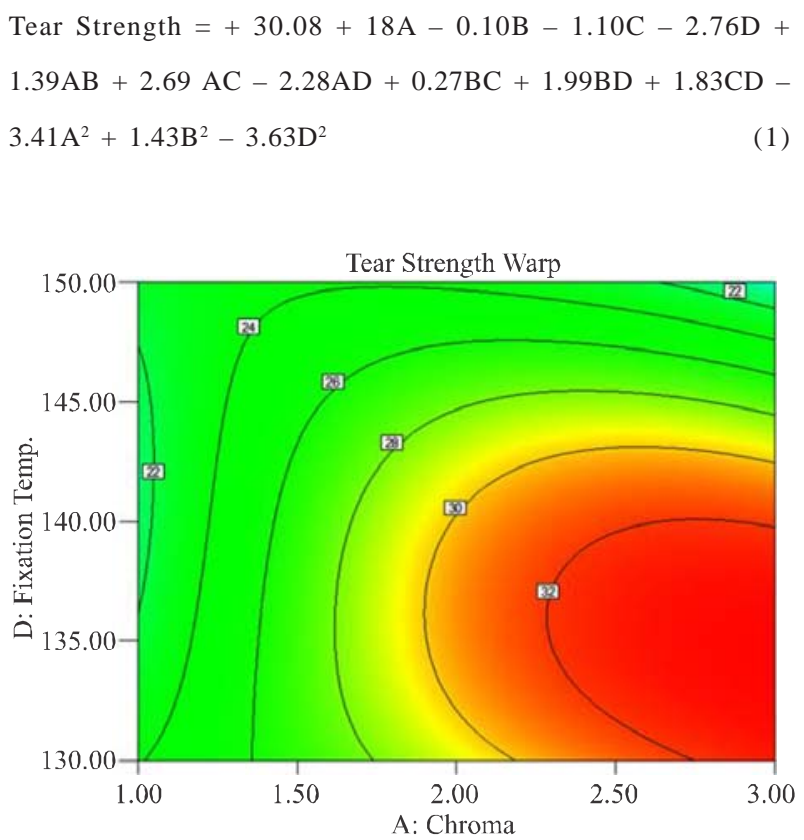

FIG. 6. CONTOUR PLOT OF DYE CONCENTRATION

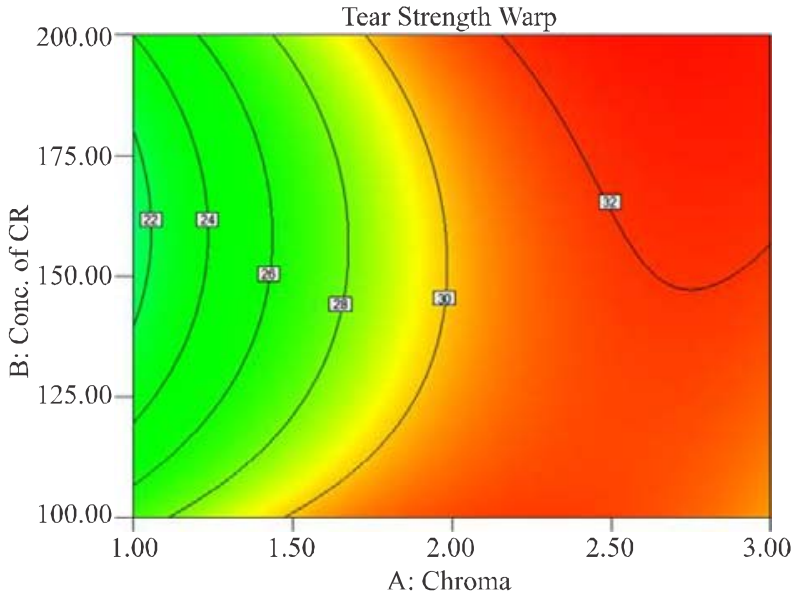

FIG. 7. CONTOUR PLOT OF DYECONCENTRATION

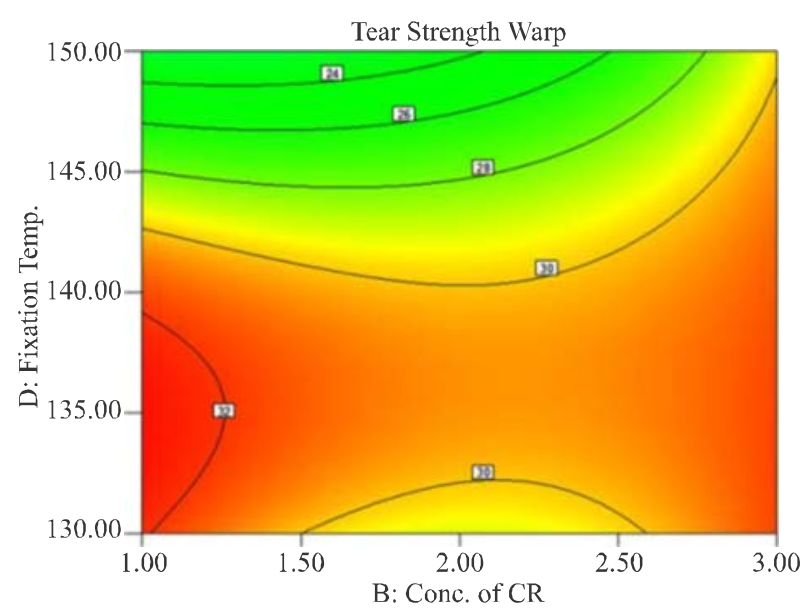

FIG. 8. CONTOUR PLOT OF CONCENTRATION OFCREASERESISTANT AND FIXATION TEMPERATURE

\section{CONCLUSION}

The statistical analysis of various factors revealed the quadratic effect of significant factors and interactions on the tear strength of one step fixation process. Furthermore, the model had been tested for adequacy and found that the assumption of normality and independency are not violated. $\mathrm{R}^{2}$ values were very high, suggesting that models accounted for most of the variability.The developed equation of tear strength modeled the relationship of significant factor and interaction on the tear strength. The high values of coefficient of determination implied that the predicted statistical model will effectively depict the tear strength of single step fixation process over the range of values. It had been found from the plots of vital interactions that one step fixation process using an Econtrol method at $130-135^{\circ} \mathrm{C}$ yields higher values of tear strength.

\section{ACKNOWLEDGEMENTS}

The authors wish to express their gratitude to NED University of Engineering \& Technology, Karachi, Pakistan, for providing research grant and logistics, Gul Ahmed Textile Mills Ltd., and Archroma Pakistan Ltd., Karachi, for carrying out the necessary experimental work. 


\section{REFERENCES}

[1] Tavanail, H., Taheri, S.M., and Nasiri, M., "Modelling of Colour Yield in Polyethylene Terephthalate Dyeing with Statistical and Fuzzy Regression”, Iranian Polymer Journal, Volume 14, No.11, pp.954-967, 2005.

Tavanai, H., Hamadani, A.Z., and Askari, M., "Modelling of Colour Yield for Selected Reactive Dyes in Dyeing Cotton Cloth by Two Phase Pad-steam Method”, Iranian Polymer Journal, Volume15, No. 3, pp. 207-217, 2006.

[3] Vassileva, V., Valcheva, E., and Zheleva, Z., “The Kinetic Model of Reactive Dye Fixation on Cotton Fibres", Journal of the University of Chemical Technology and Metallurgy, Volume 43, No. 3, pp. 323-326, 2008.

[4] Chakraborty, A., and Dutta, C., "Kinematics of Concurrent Dyeing and Finishing - A Critical Study", Proceedings of International Conference on Energy \& Environment, March, 2009. Step Dyeing and Finishing Treatment of Cotton with 1, 2, 3, 4-Butanetetracarboxylic Acid”, Journal of Applied Polymer Science, Volume 54, No.13, pp. 2107-2118, 1994.

Dong, Y., Wang, J., and Liu, P., "Dyeing and Finishing of Cotton Fabric in a Single Bath with Reactive Dyes and Citric Acid”, Coloration Technology, Volume 117, No. 5, pp.262-265, 2001.

El-Hamaky, Y.H., Tawfeek, S., Ibrahim, D.F., Maamoun, D., and Gaber, S., "Printing Cotton Fabrics with Reactive Dyes of High Reactivity from an Acidic Printing Paste”, Coloration Technology, Volume 123, No. 6, pp. 365-373,2007.

[8] Ahmed, N.S.E., Yourself, Y.A., El-Shishtawy, R.M., and Mousa, A.A., "Urea/Alkali Free Printing of Cotton with Reactive Dyes”, Coloration Technology, Volume 122, No. 6, pp. 324-328, 2006.

Yang, Y., and Naarani, V., "Effect of Steaming Conditions on Colour and Consistency of Ink-Jet Printed Cotton Using Reactive Dyes”, Coloration Technology, Volume 120, No. 3, pp. 127-131, 2004.

Yuen, C.W.M., Ku, S.K.A., Choi, P.S.R., and Kan, C.W., "Study of the Factors Influencing Colour Yield of an Inkjet-Printed Cotton Fabric”, Coloration Technology, Volume 120, No. 6, pp. 320-325, 2004.

Can, Y., Akaydin, M., Turhan, Y., and Ay E., "Effect of Wrinkle Resistance Finish on Cotton Fabric Properties”, Indian Journal of Fibre \& Textile Research, Volume 34, pp. 183-186, 2009.

[12] Mortazavi, S.M., and Boukany, P.E., “Application of Mixtures of Resin Finishing to Achieve Some Physical Properties on Interlining Cotton Fabrics: I-Effect of Stiffening and Cross-Linking Agents”, Iranian Polymer Journal, Volume 13, No. 3, pp.213-218, 2004.

[13] Asim, F., and Mahmood, M., "Reactive Printing \& Crease Resistance Finishing of Cotton Fabrics. Part-I Study of Influential Factors by an Experimental Design Approach”, Journal of Textile \& Apparel, Technology and Management, Volume 7, No. 1, 2011.

[14] Asim, F., and Mahmood, M., "Reactive Printing and Crease Resistance Finishing of Cotton Fabrics-Effects of Fixation Modes by $2^{2} .4^{1}$ Mixed Factorial Design”, International Journal of Textile Science, No. 6, pp. 94-100, 2012.

[15] Mortazavi, S.M., Alsharif, M.A., and Jannesari, M.,”A Study on Simultaneous Fixation of Reactive Dye Printing and Crease Resist Finishing on Cotton Fabric (Effect of DMDHEU Concentration, Types of Catalyst and Drying Conditions)", http://140.134.132.124:8080/dspace/ bitstream/2377/3912/1/ce05atc902007000039.pdf 
[16] Asim, F., and Mahmood, M., "Effects of Process Parameters on Single Step Fixation of Reactive Printing and Crease Resistance Finishing of Cotton Fabrics using $2^{3}$ Factorial Design”, International Journal of Textile Science, Volume 2, No. 1, pp. 7-11, 2013.
[17] Asim, F., "Development of a Combined Process for Reactive Printing and Crease Resistance Finish for Cotton Fabric using Experimental Design Technique”, Doctoral Thesis, Department of Textile Engineering, NED University of Engineering \& Technology, Karachi, Pakistan, 20112. 